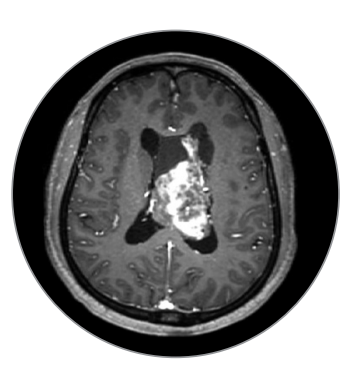

\section{Neurocitoma central: presentación de un caso}

\author{
Central Neurocytoma: A Case Report
}

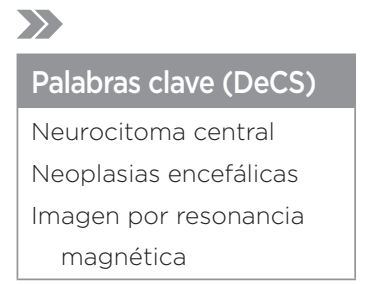

\section{Key words (MeSH)}

Central neurocytoma

Brain neoplasms

Magnetic resonance

imaging
'Residente de Radiología, Hospital Clínico Quirúrgico Docente "Hermanos Ameijeiras". La Habana, Cuba.

Especialista en Radiología, Hospital Clínico Quirúrgico Docente "Hermanos Ameijeiras". Universidad de Ciencias Médicas de La Habana, Cuba.

${ }^{3}$ Licenciado en Tecnología de Imagenología, Hospital Clínico Quirúrgico Docente "Hermanos Ameijeiras". Universidad de Ciencias Médicas de La Habana, Cuba.

\title{
Resumen
}

El neurocitoma central es un tumor raro, de muy baja incidencia y de pronóstico favorable. Su presentación radiológica muestra similitudes con otros tumores cerebrales. Se describe el caso de un paciente de 36 años con diagnóstico incidental de neurocitoma central intraepitelial. Después de 13 años del diagnóstico el paciente refiere sintomatología clínica de cefalea y bradipsiquia. El paciente rechazó la cirugía. El diagnóstico y seguimiento es posible mediante imagen por resonancia magnética con espectroscopia.

\section{Summary}

Intraepithelial central neurocytoma is a rare tumor, with very low incidence and favorable prognosis. Its radiological presentation shows similarities with other brain tumors. The case of a 36-year-old patient with an incidental diagnosis of central intra-epithelial neurocytoma is described. After 13 years of diagnosis the patient refers clinical symptoms of headache and bradypsychia. The patient refused surgery. Diagnosis and follow-up is possible by means of magnetic resonance imaging with spectroscopy.

\section{Introducción}

El neurocitoma central se considera una neoplasia benigna de localización intraepitelial. La Organización Mundial de Salud (OMS) lo clasifica como un tumor de grado II. Su incidencia es inferior al 0,5\% de todos los tumores cerebrales (1), y tiene mayor prevalencia en adultos jóvenes, con una mediana de 34 años de edad (2). Hassoun y colaboradores (3) lo describieron por primera vez en 1982, como tumor benigno con características histopatológicas y radiológicas distintivas de otras neoplasias intraventriculares. El tratamiento de elección es la cirugía, con resección completa del tumor. La radioterapia como tratamiento adyuvante se indica en casos donde no es posible la resección completa (2).

\section{Presentación de caso}

Paciente masculino, de 36 años de edad, con antecedentes familiares de hipertensión arterial en ambos padres. Como sintomatología refiere cefalea frontal izquierda, que se intensifica con cambios de posición, con irradiación a región occipitocervical, además, bradipsiquia. El paciente había sido llevado al hospital en el año 2006 por un trauma craneoencefálico en la región occipital, con pérdida de conciencia. Se le realizó tomografía axial computarizada (TAC) simple de cráneo en la que se encontró lesión expansiva intraventricular de gran tamaño, con mayor crecimiento hacia el cuerno frontal izquierdo. Posteriormente, realizaron biopsia de la lesión por vía endoscópica a través del cuerno frontal, con resultado de neurocitoma central intraventricular.
En esta nueva consulta se le tomaron imágenes por resonancia magnética (RM) cerebral con medio de contraste con gadolinio más espectroscopia.

En el estudio de RM del 22 de marzo de 2019, se aprecia lesión expansiva intraventricular de gran tamaño, con mayor crecimiento hacia el cuerno frontal izquierdo, que produce ligera dilatación ventricular, con líquido en su interior con baja señal en T1 (figura 1), heterogéneo con predominante alta señal en secuencias con información T2 (figura 2). En el estudio posgadolinio, los dos tercios posteriores de tumor se intensifican con el medio de contraste de forma homogénea (figura 3 ).

En la espectroscopia se observa un aumento de la colina, con disminución de N-Acetilaspartato en el centro de la lesión y en el borde izquierdo de la misma; se observa aumento del mioinositol en todo el tumor, lo cual sugiere un tumor de bajo grado (figura 4). No se le practicó cirugía por temor a las complicaciones.

\section{Discusión}

Los tumores intraventriculares debutan con sintomatología clínica de cefalea, vómito, déficit visual y de memoria por hipertensión intracraneal $(1,2)$. El diagnóstico en el caso presentado ocurre de manera incidental, debido a un trauma craneal. Durante los 13 años de seguimiento solo refiere cefalea y bradipsiquia. La duración de los síntomas puede variar desde días hasta años y está principalmente asociada a la localización del tumor (2).

Para la clasificación de los tumores cerebrales, el análisis histopatológico es el procedimiento de elección. 

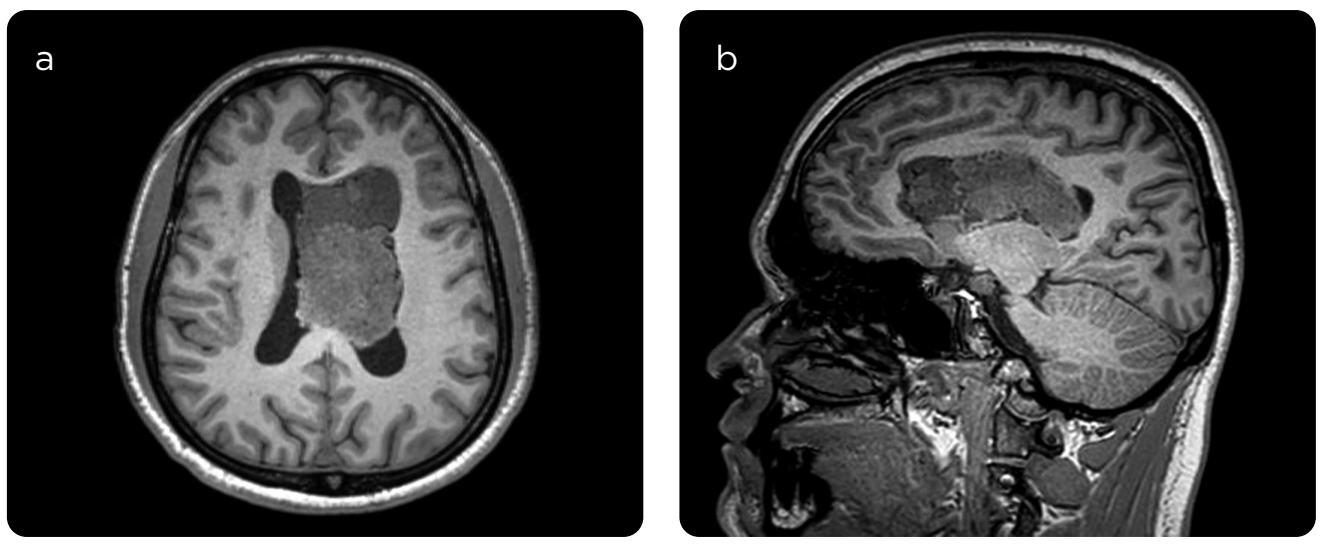

Figura 1. Neurocitoma central. RM a y b) axial y sagital con información T1. gran masa lobulada intraventricular, heterogénea, predominantemente isointensa respecto a la sustancia gris, con extensión al tercer ventrículo y a ventrículos laterales, con predominio en el lado izquierdo.

Figura 2. Neurocitoma central. RM a y b) axial y sagital con información T2. Masa heterogénea, con múltiples focos de alta señal pequeños, con aspecto característico de "burbujas" o de "pompas de jabón".
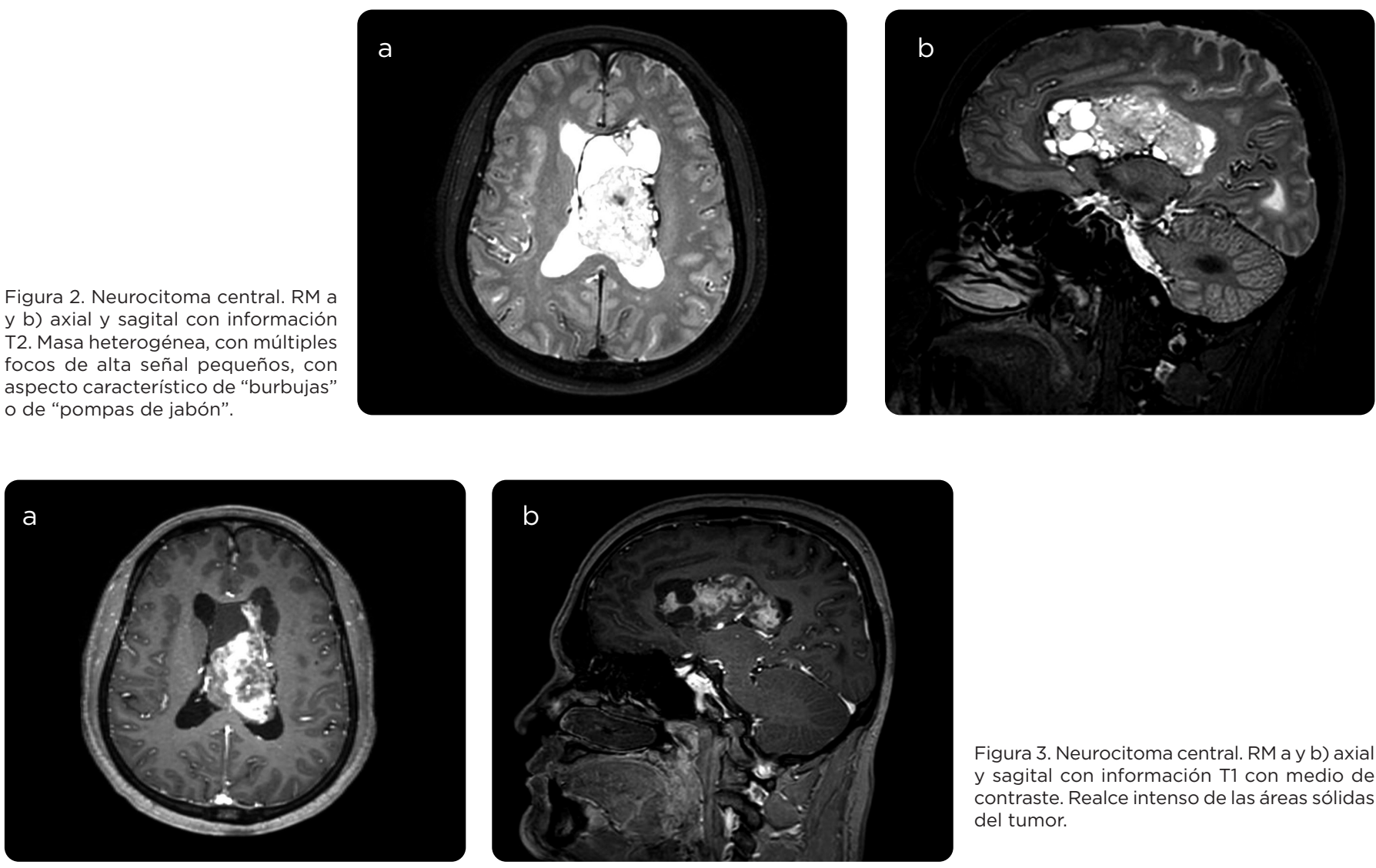

Figura 3. Neurocitoma central. RM a y b) axial y sagital con información T1 con medio de contraste. Realce intenso de las áreas sólidas del tumor.

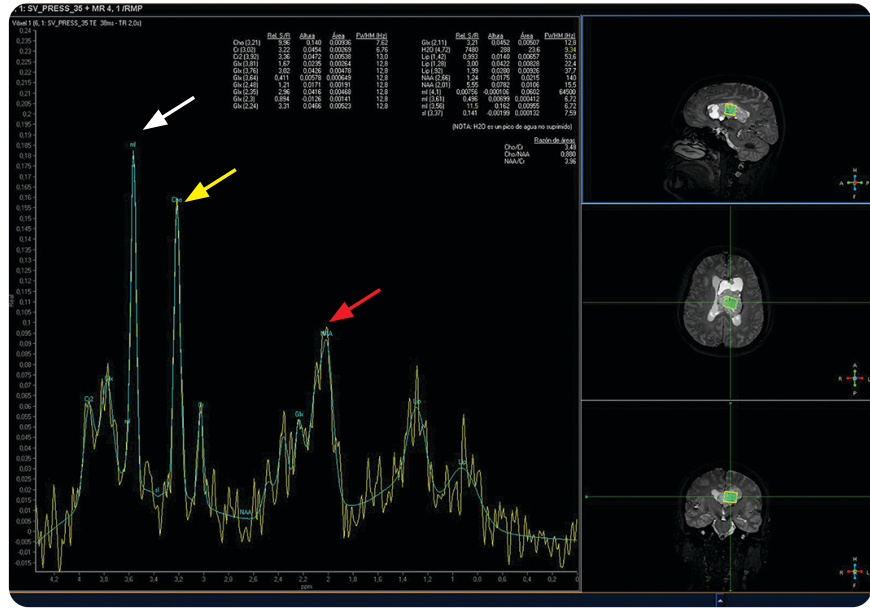

Figura 4. Espectroscopia de un neurocitoma central con aumento en el pico de colina (flecha amarilla) y en el mioinositol (flecha blanca), disminución en el pico de $\mathrm{N}$-Acetilaspartato (flecha roja). 
Las imágenes por TAC (4) y RM tienen utilidad en el diagnóstico diferencial; sin embargo, no se documentan estudios de correlación entre los resultados de las imágenes e histología $(2,5)$. Un signo radiológico característico del neurocitoma es la hidrocefalia (4), pero en este caso se observa solo ligera dilatación ventricular. En la RM el neurocitoma central se muestra de señal baja a intermedia en secuencias con información T1, y de señal intermedia a alta en secuencias con información T2. La baja señal en secuencias con información T2 puede indicar hemorragia, quiste o calcificación (2,6). En el caso presentado, la RM mostró zonas de baja señal en secuencias con información T1 y de alta señal en secuencias con información T2, lo cual se corresponde con el patrón descrito.

La espectroscopia por RM es importante para estimar cambios en los metabolitos. Los niveles elevados de colina se observan en los tipos más agresivos de neurocitomas y la disminución de N-Acetilaspartato es un indicador de pérdida de células neuronales intactas (6), lo cual fue confirmado en el caso que se presenta en este trabajo.

El tratamiento de elección es la resección quirúrgica con radioterapia convencional o radiocirugía en casos de resección incompleta o recurrencia $(1,4)$. La resección completa es posible en el 30-50 \% de los pacientes, con una tasa de supervivencia a 5 años del $99 \%$; en los pacientes con resección parcial, se informa una tasa del $86 \%$ a 5 años (2). Imber y colaboradores (7) evaluaron una cohorte histórica de 28 pacientes con neurocitoma. En el $32 \%$ se realizó resección completa de la lesión y en el $68 \%$ resección subtotal. El paciente del caso presentado no aceptó la cirugía. Tiene 13 años de evolución, con sintomatología clínica estable en el tiempo.

Teniendo en cuenta que la incidencia varía entre el $0,1 \%$ y $0,5 \%$ se considera relevante contribuir al estado del arte de esta patología con esta presentación

\section{Conclusiones}

El neurocitoma central intraepitelial es una patología de rara aparición, por lo tanto, no existen estudios que permitan establecer una conducta óptima de tratamiento. Resulta de vital importancia tenerlo en cuenta en el diagnóstico diferencial de las lesiones intraventriculares, para definir la conducta a seguir.

El avance de los estudios radiológicos facilita el diagnóstico y la espectroscopia puede ser importante en la confirmación del mismo. Resulta interesante la evolución favorable del paciente, sin haber recibido el tratamiento quirúrgico.

\section{Referencias}

1. Rodríguez de Lope A, de La Lama A, López-Ariztegui N, et al. Tratamiento del neurocitoma central. Experiencia en nuestro centro. Neurocirugía. 2004;15:128-37.

2. Lee SJ, Bui T, Hai C, Chen J, et al. Central neurocytoma: A review of clinical management and histopathologic features. Brain Tumor Res Treat. 2016;4(2):49-57.

3. Hassoun J, Gambarelli D, Choux M, et. al. Complex cerebral tumor with evidence of neuronal, glial and Schwann cell differentiation. Cancer. 1982;49:1420-8.

4. González JL, Ayala JR, Suárez T, et al. Neurocitoma intraventricular. Reporte de dos casos y análisis de posibilidades Terapéuticas. Gac Méd Méx. 1999;135(3):317-21.

5. Saldívar-Rodea CA, Guerrero-Avendaño GM, Benítez-Barradas MI, Reyes-Caldelas MA. Utilidad de la resonancia magnética en el diagnóstico y clasificación de los tumores astrocíticos. Anales de Radiología México. 2016;15(4):279-93.

6. Chuang MT, Lin WC, Tsai HY, et al. 3-T Proton magnetic resonance spectroscopy of central neurocytoma: Case reports and review of the literature. J Computer Assisted Tomography. 2005;29:683-8.

7. Imber BS, Braunstein SE, Wu FY et.al. Clinical outcome and prognostic factors for central neurocytoma: twenty year institutional experience. Neurooncol. 2016;126(1):193-200.

\section{Correspondencia}

José Luis Sánchez Peña

Departamento de Radiología e Imágenes Diagnósticas

Hospital Clínico Quirúrgico Docente "Hermanos Ameijeiras"

Calle San Lázaro \# 701 esquina a Belascoain, piso 5

La Habana, Cuba

mdjsp@hotmail.com

Recibido para evaluación: 15 de octubre de 2019

Aceptado para publicación: 1 de diciembre de 2019 